\title{
Spectroscopic Determination of Cytochrome c Oxidase Content in Tissues Containing Myoglobin or Hemoglobin
}

\author{
Robert S. Balaban, Vamsi K. Mootha, and Andrew Arai \\ Laboratory of Cardiac Energetics, National Heart Lung and Blood Institute, National Institutes of Health, \\ Building 10, Room B1D-161, Bethesda, Maryland 20892
}

Received February 23, 1996

A simple spectroscopic method for determining the cytochrome c oxidase, cytochrome $a, a_{3}$, content in tissue and mitochondria samples independent of myoglobin or blood contamination is described. Using tissue homogenates solubilized in Triton X-100, this assay relies on the selective reduction of mitochondrial cytochromes by the action of potassium cyanide. Monitoring the optical absorbance of these samples at $605 \mathrm{~nm}$ provided a quantitative determination of cytochrome c oxidase content in the presence of myoglobin or blood. The cytochrome c oxidase content of porcine heart mitochondria and whole tissue was determined to be $0.85 \mathrm{nmol} / \mathrm{mg}$ protein and $30.5 \mathrm{nmol} / \mathrm{g}$ wet wt, respectively. $\odot 1996$ Academic Press, Inc.

The determination of cytochrome c oxidase, or cytochrome $a, a_{3}$, in biological tissues is a useful marker of mitochondrial content and oxidative metabolism adaptations (1-3). There are two approaches for determining cytochrome oxidase in tissues. One approach is to determine the enzymatic activity via reduced cytochrome $c$ stimulation of oxygen consumption $(4,5)$ or cytochrome c oxidation directly (5) in specially prepared tissue homogenates. Another method relies on quantitative spectrophotometric determination of cytochrome c oxidase content in nonionic detergent-treated homogenates (6) or complex treatments of crude tissue homogenates (14). The quantitative spectrophotometric method is the only procedure which provides an absolute concentration of cytochrome oxidase. In addition, this absolute spectrophotometric determination can be performed without complications associated with proper tissue fractionation and modification of enzymatic activity.

A quantitative spectrophotometric approach for determining mitochondrial cytochromes in tissue samples was described by Williams (6). Using this approach, homogenized tissue is dissolved into a $2 \%$
Triton X-100 solution to eliminate light scattering effects. The differential absorbance at 605 and $630 \mathrm{~nm}$ during chemically induced maximum oxidation and reduction of the sample was used to determine the absolute concentration of cytochrome oxidase content. The oxidation is usually performed with a strong oxidizing agent, such as ferricyanide, while the reduction is accomplished with ascorbate in combination with sodium hydrosulfite. This approach has been successfully used in numerous mitochondrial preparations (2) as well as tissues including liver (6) and kidney (1). However, we have found that in tissues containing myoglobin, such as heart or skeletal muscle, this approach overestimates the cytochrome c oxidase content due to the contribution of myoglobin to the oxidation-reduction difference spectrum. Hemoglobin from blood contamination during tissue isolation or biopsy procedures can lead to similar errors.

The purpose of this study was to develop a method of determining cytochrome c oxidase content in tissue homogenates in the presence of myogl obin or hemogl obin. We have found that the selective spectrophotometric effects of cyanide on cytochrome c oxidase in detergenttreated homogenates provide a simple and accurate assay for cytochrome c oxidase content.

\section{MATERIALS AND METHODS}

Pig hearts were collected from chloralose (100 mg/ kg intravenously)-anesthetized animals after a midline thoracotomy. The animals were heparinized $(10,000$ units intravenously) prior to harvesting the heart. The heart was then immediately perfused via the aorta in a retrograde fashion with 1 liter of isolation medium (0.3 $\mathrm{M}$ sucrose, $10 \mathrm{~mm}$ Hepes, $0.2 \mathrm{~mm} \mathrm{~K}_{2}$ EDTA, pH 7.2) at $5^{\circ} \mathrm{C}$. The left ventricle was dissected free from fat, large vessels, and the right ventricle free wall. Approximately $5 \mathrm{~g}$ of heart muscle was taken for tissue homogenization, while the remaining myocardium was used 
for mitochondria isolation. This procedure permitted the direct comparison of heart tissue and mitochondria collected from the same animal.

The tissue homogenization was performed by placing a sample of heart muscle $(\sim 5 \mathrm{~g})$ in an equal weight of $0.1 \mathrm{M}$ sodium phosphate buffer at $\mathrm{pH}$ 7.0. The tissue was then minced with scissors at $5^{\circ} \mathrm{C}$. This mixture was then homogenized using two 5-s treatments at maximum speeds with a tissue homogenizer (Virtis, Gardiner, NY) at $5^{\circ} \mathrm{C}$. Excessive treatment in the homogenizer or permitting high temperatures during homogenization resulted in the generation of oxidized myoglobin, which should be avoided (see Results). Approximately 1-ml samples of the homogenate were weighed and then dissolved in $5 \mathrm{ml}$ of $2 \%(\mathrm{v} / \mathrm{v})$ Triton $X-100$ in $0.1 \mathrm{~m}$ sodium phosphate buffer ( $\mathrm{pH} 7.0)$. After mixing, the suspension was centrifuged to remove any residual connective tissue and solid material. The resulting pellet was white with no evidence of unlysed material. The solid material composed of less than 3\% of the total volume based on wet weight-dry weight ratios. No correction for this fractional volume was made in the calculations. This supernatant was then directly used in the spectrophotometric cytoch rome oxidase assays discussed below. Protein analysis revealed a concentration of $140 \pm 20 \mathrm{mg}$ protein/g wet weight in these homogenates. The wet weight to dry wet ratio was $4.7 \pm 0.3$.

Heart mitochondria were prepared as previously described (7). The final mitochondrial incubation medium was $130 \mathrm{~mm} \mathrm{KCl}, 20 \mathrm{~mm}$ Hepes, $2.5 \mathrm{~mm} \mathrm{M} \mathrm{gCl}_{2}, 0.5 \mathrm{~mm}$ $\mathrm{K}_{2} \mathrm{EDTA}, \mathrm{pH}$ 7.2. Respiratory rates were determined at $37^{\circ} \mathrm{C}$ in a sealed glass chamber with a Clark oxygen electrode (Yellow Springs, Yellow Springs, $\mathrm{OH}$ ) using a solubility of $\mathrm{O}_{2}$ of $199 \mathrm{nmol} \mathrm{O}_{2} / \mathrm{ml}$. The respiratory quotient (State 3/State 4) ranged from 8 to 9 . For the cytochrome oxidase assay, 11 to $18 \mathrm{mg}$ of mitochondrial protein ( $1 \mathrm{ml}$ of mitochondria stock solution) was dissolved in 2 or $3 \mathrm{ml}$ of $2 \%$ Triton $\mathrm{X}-100$ in $0.1 \mathrm{M}$ phosphate buffer at pH 7.0. No centrifugation was necessary in these samples since no solid matter was observed. These samples were then directly used in the spectrophotometric assay for cytochrome oxidase. Protein was determined by the biuret method (8).

One milliliter of Triton X-100-solubilized tissue or mitochondria was placed in two spectrophotometric cuvettes. These were then placed in a spectrophotometer (Perkin Elmer, Norwalk, CT) and all measurements were made as the optical absorbance differences between the two cuvettes. Typically, chemical modifications were only made to one cuvette (experimental cuvette) with the other serving as a reference. Difference spectra were recorded on a strip chart recorder as well as digitized using an A/D converter (Strawberry Tree, Sunnyvale, CA) interfaced with a computer (Apple Computers. Cupertino, CA). The OD was calculated

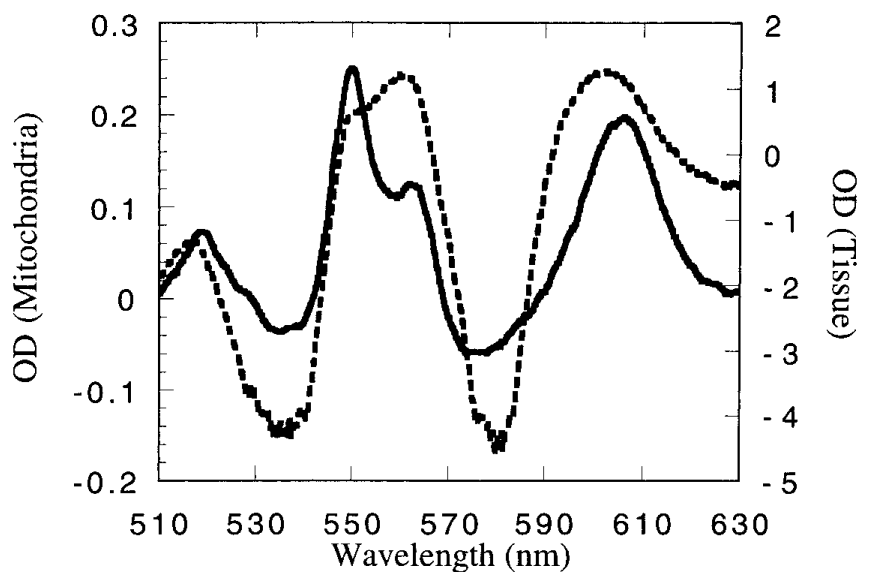

FIG. 1. Effect of sodium hydrosulfite on the optical absorbance of heart tissue (broken line) and mitochondria (solid line) Triton X-100treated preparations. All spectra presented are difference spectra of the reference cuvette versus the experimental cuvette. Difference spectra were collected versus untreated control cuvette with appropriate water additions to keep tissue concentration constant. Heart tissue sample contained $0.063 \mathrm{~g}$ wet $\mathrm{wt} / \mathrm{ml}$. Mitochondria contained $4.65 \mathrm{mg}$ protein/ml. OD is the optical density difference between the two cuvettes in this and all following figures.

from the difference in absorbance at 630 versus 605 or in samples with a drifting baseline the difference from a baseline drawn between 630 and $575 \mathrm{~nm}$ (see (9)). All data presented in figures show the optical difference (OD) between the reference and experimental cuvette.

\section{RESULTS}

In whole tissue homogenates, addition of sodium hydrosulfite to one of the cuvettes resulted in a difference spectrum which was characteristic of a combination of both cytochromes and myoglobin. This is most apparent when a tissue sample spectrum is compared directly with a mitochondrial preparation which does not contain myoglobin, as shown in Fig. 1. Since myogl obin contributes significantly to the absorbance at $605 \mathrm{~nm}$, the presence of myogl obin results in the overestimation of the cytochrome oxidase contribution when the standard 605- 630 wavelength pair is used.

Since cytochrome oxidase is active in nonionic detergents (see Ref. 4), we reasoned that the addition of potassium cyanide should prevent the oxidation of cytochrome by oxygen and result in a selective reduction of cytochrome $c$ oxidase which could be observed at $605 \mathrm{~nm}$. Low concentrations of cyanide do not interact significantly with ferric hemoglobin or myoglobin (10). Consistent with this notion, oxygen consumption in Triton X-100-treated homogenates was stimulated $(\sim 300 \%)$ by sodium ascorbate (15 mm) and inhibited $(\sim 50 \%)$ by cyanide ( $2 \mathrm{~mm}$ ) in the presence of ascorbate. As shown in Fig. 2, potassium cyanide ( $2 \mathrm{~mm})$ added 


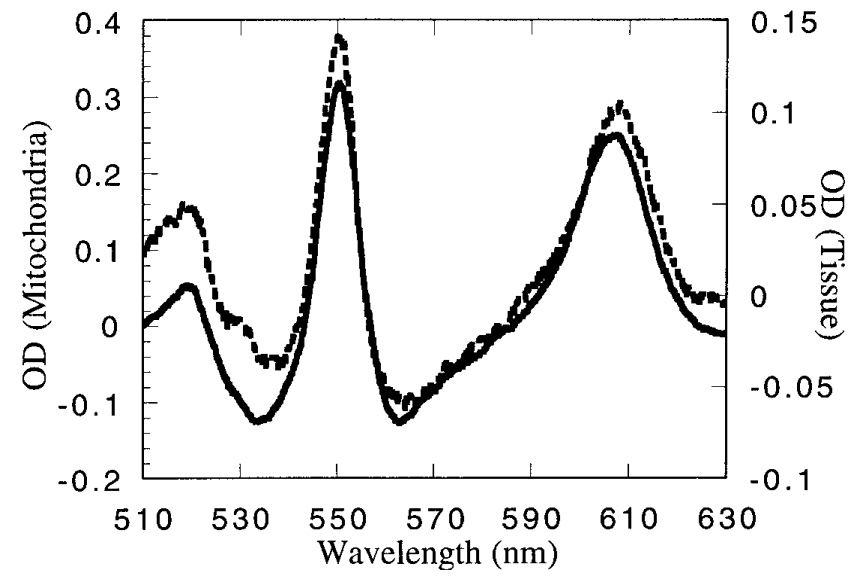

FIG. 2. Effect of $2 \mathrm{~mm}$ potassium cyanide on the optical properties of heart tissue (broken line) and mitochondria (solid line) preparations. Difference spectra were collected versus untreated control cuvette with appropriate water additions to keep the tissue concentration constant. The mitochondria concentration was $4.65 \mathrm{mg}$ protein/ $\mathrm{ml}$. The heart tissue concentration was $0.070 \mathrm{~g}$ wet $\mathrm{wt} / \mathrm{ml}$.

to the Triton X-100-solubilized tissue or mitochondria resulted in identical spectral characteristics consistent with a cytochrome $\mathrm{c}$ and cytochrome $\mathrm{c}$ oxidase reduction-oxidation difference spectrum. Absorption maxima were observed at $605 \mathrm{~nm}$ (cytochrome c oxidase), $550 \mathrm{~nm}$ (cytochrome c), and $520 \mathrm{~nm}$ (combinations of both cytochromes). The reduction of cytochrome c oxidase was complete in $5 \mathrm{~min}$ at $24^{\circ} \mathrm{C}$. These data suggest that cytochrome $\mathrm{c}$ was being oxidized by cytochrome $\mathrm{c}$ oxidase in Triton X-100 and that cyanide blocked this process. Over a long period of time (10 to $15 \mathrm{~min}$ ), an absorbance at $563 \mathrm{~nm}$, consistent with cytochrome b, was also observed. This suggests that even the oxidation of cytochrome b was still linked to cytochrome c oxidase in these preparations.

The reducing equivalent dependence of the cyanide effect was confirmed by adding $50 \mu$ l of $0.05 \mathrm{M}$ potassium ferricyanide to both cuvettes before the addition of cyanide to completely oxidize the environment. Under these oxidizing conditions, only weak absorbance bands in the 548- and 584-nm regions were observed consistent with a spin state transition in the ferric heme of cytochrome, as described by Wilson et al. (11) under similar conditions in intact mitochondria. The need for reducing equivalents in this process was further confirmed by the addition of $15 \mathrm{~mm}$ sodium ascorbate which slightly reduced cytochrome coxidase under control conditions and increased the rate of cytochrome reduction in the presence of cyanide (not shown). However, ascorbate did not increase the maximum absorbance at $605 \mathrm{~nm}$ in the presence of cyanide in either mitochondria or tissue preparations nor did ascorbate alter the spectral characteristics.

The effect of cyanide on mitochondria preparations was directly compared to the standard sodium hydrosulfite reduction procedure to determine the extent of cytochrome reduction by cyanide. In Fig. 3 difference spectra collected with cyanide or sodium hydrosulfite are shown. Except for the cytochrome b absorbance bands observed at 563 and $530 \mathrm{~nm}$, the cyanide and hydrosulfite spectra were nearly identical in terms of spectral shape and absorbance magnitude. The cyanide treatment resulted in a slightly lower (10\%) absorbance at 605 when compared to sodium hydrosulfite as observed by Van Buuren et al. (12). These investigators demonstrated that the oxygenated-deoxygenated extinction coefficient of cyanocytochrome oxidase is $10 \%$ lower than the native enzyme. This is likely due to the contribution of cytochrome $a_{3}$ in the sodium hydrosulfite spectrum and not in the cyanide spectrum since it
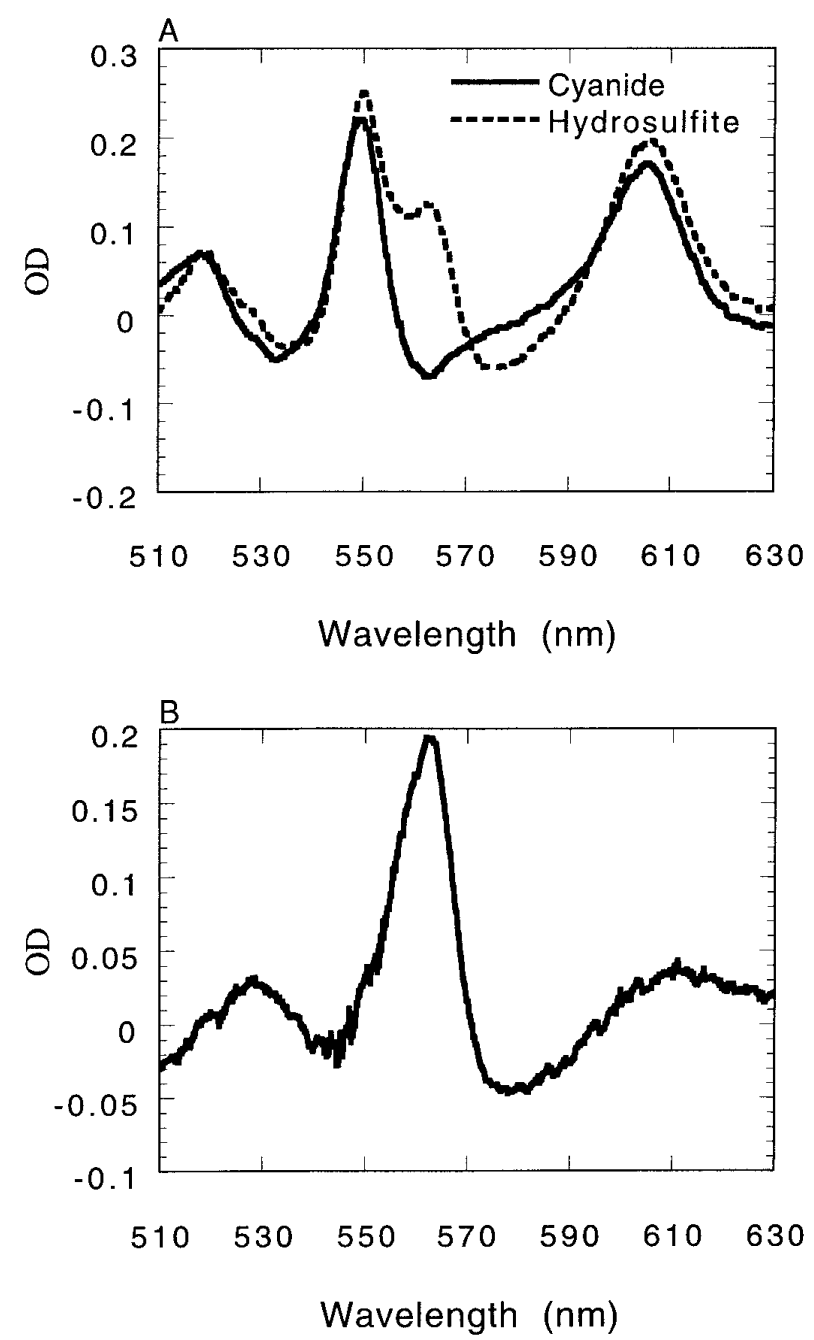

FIG. 3. Effect of potassium cyanide and sodium hydrosulfite on the absorption spectra of solubilized mitochondria. Mitochondria concentration was $4.65 \mathrm{mg}$ protein $/ \mathrm{ml}$. (A) Difference spectrum was obtained with $2 \mathrm{~mm}$ cyanide or sodium hydrosulfite. (B) Difference spectrum of the data presented in A. 
TABLE 1

Cytochrome Oxidase Content in Porcine Heart Tissue and Mitochondria

\begin{tabular}{cll}
\hline Sample & Reducing agent & Cytochrome oxidase content \\
\hline Mitochondria & Cyanide $(\mathrm{n}=12)$ & $0.84 \pm 0.058 \mathrm{nmol} / \mathrm{mg} \mathrm{protein}$ \\
Mitochondria & Hydrosulfite $(\mathrm{n}=6)$ & $0.85 \pm 0.055 \mathrm{nmol} / \mathrm{mg} \mathrm{protein}$ \\
Heart tissue & Cyanide $(\mathrm{n}=17)$ & $30.5 \pm 1.6 \mathrm{nmol} / \mathrm{g}$ wet wt \\
\hline
\end{tabular}

Note. The millimolar extinction coefficient for cytochrome oxidase varies in the literature from $26 \mathrm{OD}^{-1} \mathrm{~cm}^{-1}(15)$ to $12 \mathrm{OD}^{-1} \mathrm{~cm}^{-1}(6)$. The millimolar extinction coefficients used for the difference spectra in this table were $12 \mathrm{OD}^{-1} \mathrm{~cm}^{-1}$ for sodium hydrosulfite and $10.8 \mathrm{OD} \mathrm{O}^{-1}$ $\mathrm{cm}^{-1}$ for potassium cyanide. $\pm \mathrm{SD}$.

complexes with cyanide. This condusion was supported by the observation that sodium hydrosulfite, added after cyanide, did not result in a 10\% increase in 605 absorbance due to the high retention of cyanide to cytochrome $a_{3}$ in the presence of excess cyanide (12). From these data, we assumed that cyanide was as effective in reducing cytochrome oxidase for quantitative spectroscopic techniques as long as this $10 \%$ correction was made. Quantitative data, using a corrected millimolar extinction coefficient for the cyanide data, are presented in Table 1. Serial dilution studies revealed a linear relationship between mitochondria and tissue content with the 605 absorbance over a 10-fold range of concentrations.

In previous studies $(1,6)$, sodium ferricyanide was added to the reference cuvette to assure complete oxidation of the cytochromes. This is extremely problematic in the presence of myoglobin since ferricyanide would also generate oxidized (i.e., ferric) myoglobin resulting in gross absorbance changes in the $600 \mathrm{~nm}$ region (Fig. 4). However, we found that the use of ferricyanide was not necessary for cytochrome oxidase since it is apparently maximally oxidized under normal isolation conditions (13). To confirm this, we found that the addition of sodium ferricyanide to the reference cuvette of a mitochondrial preparation, without myogl obin, had no effect on the absorption spectrum in the $600 \mathrm{~nm}$ region (Fig. 5). Cytochrome b was apparently partially

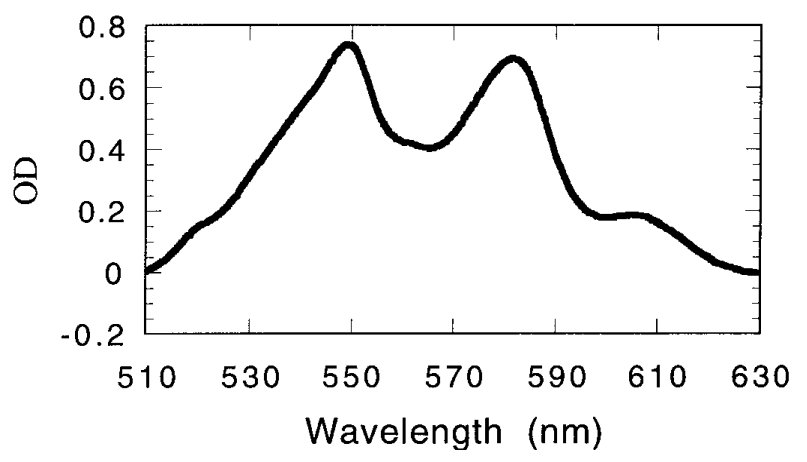

FIG. 4. Effect of ferricyanide $(2.5 \mathrm{~mm})$ on the absorbance spectrum of solubilized heart tissue. The heart tissue concentration was 0.063 $\mathrm{g}$ wet $\mathrm{wt} / \mathrm{ml}$. reduced in this preparation since an absorbance at 563 was observed with ferricyanide.

It was expected that myoglobin and hemoglobin would behave similarly with regard to cyanide and blood contamination and would not interfere with using cyanide as an "effective" cytochrome oxidase reducing agent (10). To test this hypothesis, pig blood was added to the mitochondrial preparation and the assay was performed using cyanide and sodium hyposulfite. The addition of hemoglobin had no effect on the spectral characteristics or the quantitative determination of cytochrome oxidase with cyanide. However, the he moglobin contamination greatly distorted the sodium hydrosulfite data (Fig. 6).

\section{DISCUSSION}

We have shown that the addition of cyanide to Triton X-100-solubilized mitochondria or tissue permits a quantitative spectroscopic determination of cytochrome c oxidase independent of myoglobin or blood contamination. This approach takes advantage of the ongoing cytochrome c oxidase reaction occurring in the

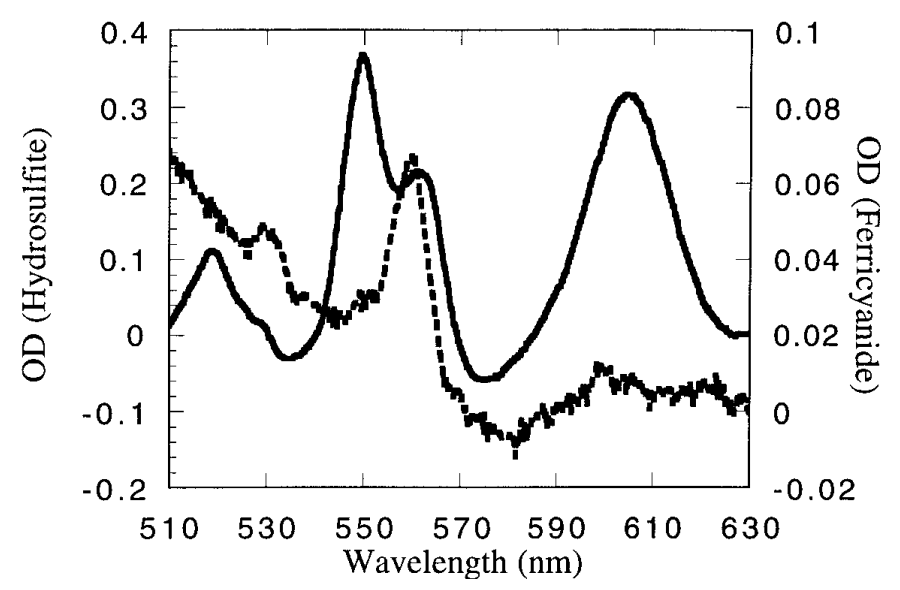

FIG. 5. Effect of ferricyanide (broken line; $2.5 \mathrm{~mm}$ ) on the absorbance spectrum of solubilized mitochondria. A sodium hydrosulfite spectrum (solid line) is also presented as a reference. The mitochondria concentration was $4.65 \mathrm{mg}$ protein $/ \mathrm{ml}$. 


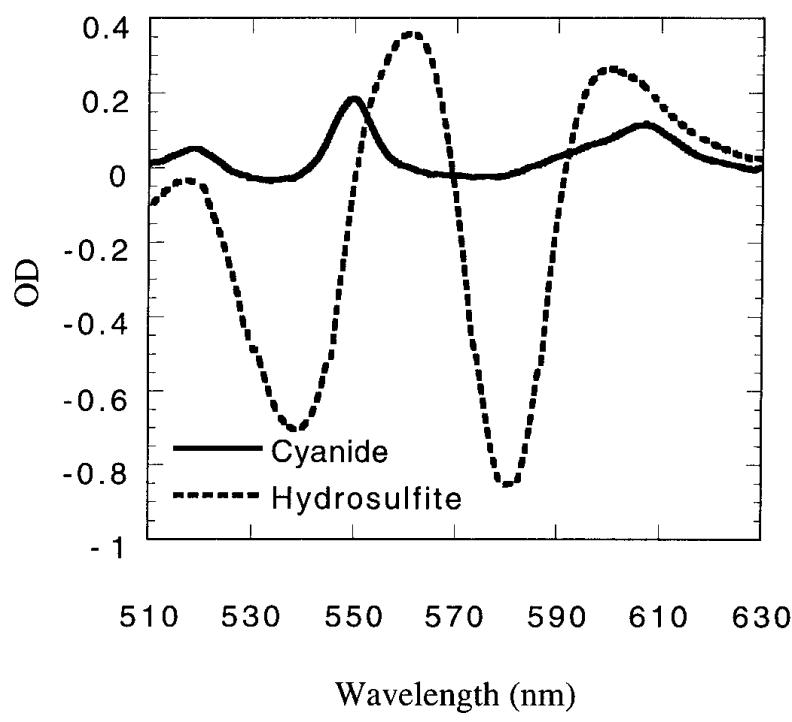

FIG. 6. Comparison of potassium cyanide and sodium hydrosulfite as reducing agents in heart mitochondria contaminated with $0.5 \mu \mathrm{g} /$ $\mathrm{ml}$ pig hemoglobin. The mitochondria concentration was $4.5 \mathrm{mg}$ protein/ml.

Triton X-100-sol ubilized preparation. This reaction utilizes reducing equivalents carried over in the solubilization process from tissue/mitochondria or with added exogenous sources. When this reaction is inhibited with cyanide, a selective and complete reduction of cytochrome $c$ and cytochrome c oxidase is observed. External reducing equivalents, such as ascorbate, were not found to be necessary for the reduction of cytochrome oxidase in this preparation, but ascorbate did increase the rate of reduction. To standardize conditions, and avoid time waiting for equilibration, we recommend the use of $10 \mathrm{~mm}$ ascorbate in these assays. Cytochrome $c$ oxidase was found to be nearly completely oxidized under control conditions eliminating the need of an external oxidizing agent, such as ferricyanide, to generate the oxidized cytochrome reference.

The simple and rapid aspects of this assay make it also feasible as a replacement to protein measurements for normalizing mitochondria content for in vitro studies. Either sodium hyposulfite or cyanide could be used as the reducing agent with appropriate extinction coefficient. Since standard curves and incubation times are required in most protein evaluations, this simple spectrophotometric technique can provide a much more rapid measure of mitochondria concentration in a single measurement.

In summary, a spectroscopic method is presented which provides a simple and rapid determination of cytochrome oxidase content in tissue samples with a high concentration of myoglobin or in blood-contaminated tissue biopsy samples.

\section{ACKNO WLEDG MENTS}

The authors thank Ms. J . Taylor and S. French for their technical help in preparing the animals and mitochondria as well as $\mathrm{Dr}$. Beatrice Wittenburg for early discussions concerning the potential optical artifacts induced by myoglobin in tissue samples. VKM was supported by the Howard Hughes Medical Institute as a NIH Research Scholar.

\section{REFERENCES}

1. Harris, S. I., Balaban, R. S., Barrett, L., and Mandel, L. J . (1981) J . Biol. Chem. 256, 10319- 10328.

2. Schwerzmann, K., Hoppeler, H., Kayar, S. R., and Weibel, E. R. (1989) Proc. Natl. Acad. Sci. USA 86, 1583- 1587.

3. Marin-Garcia, J ., and Baskin, L. S. (1989) Pediatr. Cardiol. 10, 212- 215.

4. Schnaitman, C., and Greenawalt, J. W. (1968) J . Cell. Biol. 38, 158- 175.

5. Sottocasa, G. L., Kuylenstierna, B., Ernster, L., and Bergstrand, A. (1967) J . Cell. Biol. 32, 415- 438.

6. Williams, J. N. (1964) Arch. Biochem. Biophys. 107, 537- 543.

7. Saks, V. A., Kuznetsov, A. V., Kupriyanov, V. V., Miceli, M. V., and J acobus, W. E. (1985) J . Biol. Chem. 260, 7757- 7764.

8. Skarkowska, L., and Klingenberg, M. (1963) Biochem. Z. 338, 674-694.

9. Balaban, R. S., Soltoff, S. P., Storey, J. M., and Mandel, L. J . (1980) Am. J . Physiol. 238, F50-F59.

10. Antonini, E., and Brunori, M. (1971) in Hemoglobin and Myoglobin in Their Reactions with Ligands (Neuberger, A., and Tatum, E. L., Eds.), pp. 48-49, North Holland, Amsterdam.

11. Wilson, D. F., Erecinska, M., and Brocklehurst, E. S. (1972) Arch. Biochem. Biophys. 151, 180- 187.

12. Van Buuren, K. J . H., Zuurendonk, P. F., Van Gelder, B. F., and Muijsers, A. O. (1972) Biochim. Biophys. Acta 256, 243- 257.

13. Keilin, D. (1966) The History of Cell Respiration and Cytochrome, pp. 204-251, Cambridge Univ. Press, London.

14. Nishki, K., Erecinska, M., and Wilson, D. F. (1978) Am. J . Physiol. 234 (3), C73-C81.

15. Van Gelder, B. F. (1966) Biochim. Biophys. Acta. 118, 36- 46. 